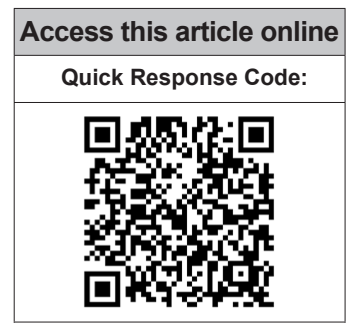

Website:

www.jponline.org

DOI:

10.4103/JLP.JLP_136_17
Division of Clinical Microscopy, Department of Medical Technology,

Research Center for Hematology and Health

Technology, Faculty of Associated Medical Sciences, ${ }^{1}$ Department of Physics and Materials

Science, Faculty of

Science, Chiang Mai University, Chiang Mai 50200, Thailand

Address for correspondence: Dr. Thanusak Tatu, Division of Clinical Microscopy, Department of Medical Technology,

Research Center for

Hematology and Health

Technology, Faculty

of Associated Medical Sciences, Chiang Mai University, Chiang Mai 50200 Thailand. E-mail: tthanu@hotmail.

Submission: 25-08-2017 Accepted: 02-01-2018

\title{
Hemolysis area: A new parameter of erythrocyte osmotic fragility for screening of thalassemia trait
}

\author{
Thanusak Tatu, Denis Sweatman ${ }^{1}$
}

\section{Abstract:}

BACKGROUND: One-tube osmotic fragility test (OFT) is widely used for screening thalassemia traits. Interobserver variation may occur with $0.36 \% \mathrm{NaCl}$-based OFT due to the naked eye result reading style.

PURPOSE: The purpose of this study was to establish and evaluate the novel numerical OFT-based parameter, so-called hemolysis area (HA), in screening thalassemia traits.

MATERIALS AND METHODS: The portable spectrophotometer was invented capable of calculating the HA values. The HA values were then compared among 69, 156, and 19 blood samples having positive, negative, and suspicious $0.36 \% \mathrm{NaCl}$-based OFT results, respectively; 109 and 135 blood samples having mean corpuscular volume (MCV) $\leq 80 \mathrm{fL}$ and $>80 \mathrm{fL}$, respectively; and 138 and 106 blood samples having mean corpuscular hemoglobin $(\mathrm{MCH}) \leq 27 \mathrm{pg}$ and $>27 \mathrm{pg}$, respectively. In addition, the $\mathrm{HA}$ values were compared in 166 blood samples having different globin gene genotypes. Finally, the HA cutoff value was determined by receiver operation curve (ROC) analysis.

RESULTS: The HA values in samples having positive, suspicious, and negative $0.36 \% \mathrm{NaCl}$-based OFT were $33.3 \pm 14.4,42.9 \pm 10.5$, and $65.3 \pm 13.4$, respectively; in sample having MCV $\leq 80 \mathrm{fL}$ and $>80 \mathrm{fL}$ were $43.1 \pm 19.6$ and $63.8 \pm 14.5$, respectively; and in samples having $\mathrm{MCH} \leq 27 \mathrm{pg}$ and $>27 \mathrm{pg}$ were $46.7 \pm 20.1$ and $64.8 \pm 14.2$, respectively. The HA values in normal, hemoglobin E, SEA- $\alpha$ thalassemia 1 , and $\beta$-thalassemia traits were $67.1 \pm 12.6,36.4 \pm 13.9,20.2 \pm 4.8$, and $18.6 \pm 1.1$, respectively. All were significantly different. ROC analysis established 52.4 as the HA cutoff that had comparable effectiveness to the conventional screening tests.

CONCLUSION: The new HA value was effective and could be an alternative choice for screening thalassemia traits.

Key words:

Hemolysis, kinetics, osmotic fragility test, thalassemia heterozygote, thalassemia screen

\section{Introduction}

Thalassemia is a chronic hemolytic 1 anemia resulting from defects of globin genes that lead to decreased or absent globin chain production. This disease is highly epidemic in the Mediterranean and tropical countries including Thailand. ${ }^{[1-3]}$ The thalassemia genes are inherited as autosomal recessive traits. Thus, those heterozygous for the thalassemia gene are clinically asymptomatic. ${ }^{[4]}$ The homozygote or

This is an open access article distributed under the terms of the Creative Commons Attribution-NonCommercial-ShareAlike 3.0 License, which allows others to remix, tweak, and build upon the work non-commercially, as long as the author is credited and the new creations are licensed under the identical terms.

For reprints contact: reprints@medknow.com compound heterozygote of the thalassemia gene may die in utero (hemoglobin $[\mathrm{Hb}]$ Bart's hydrops fetalis) or require frequent blood transfusions to maintain good quality of life (severe $\beta$-thalassemia and severe $\mathrm{HbE} / \beta$-thalassemia). Thus, early detection of thalassemia heterozygous is necessary.

One-tube osmotic fragility test (OFT) is the simple test widely used in screening thalassemia heterozygotes or thalassemia traits. Traditional OFT utilizing $0.36 \%$ $\mathrm{NaCl}$ is simple and easy to perform. However, reading the results of this OFT

How to cite this article: Tatu T, Sweatman D. Hemolysis area: A new parameter of erythrocyte osmotic fragility for screening of thalassemia trait. $\mathrm{J}$ Lab Physicians 2018;10:214-20. 
is generally based on naked eye visualization which may be prone to interobserver variation. ${ }^{[5,6]}$ The kinetic-based OFT technique that generates numerical percentage of hemolysis was developed to overcome this problem. ${ }^{[7]}$ However, this technique relied on benchtop spectrophotometer which prevented it from field use. Thus, the portable spectrophotometer that generated a novel hemolysis parameter so-called hemolysis area (HA) was invented and evaluated in this report.

\section{Materials and Methods}

The novel portable spectrophotometer with built-in data analysis capacity

The portable spectrophotometer with touchscreen control was in-house invented in a laboratory of the Department of Physics and Materials Science, Faculty of Science, Chiang Mai University. It used a high-intensity narrow beam red light-emitting diode as source and a broadband photodiode to detect the light intensity about $2 \mathrm{~cm}$ from the round cuvette position to enhance scattering sensitivity. The system used pulsed light with phase-sensitive detection to remove external light influence. An Atmel Atmega128 at $16 \mathrm{MHz}$ was used as the microcontroller and an ET-TFT240320TP-3.2 used for the touchscreen. Data were recorded at one-second intervals and displayed on screen.

The instrument measured the turbidity of the red cell suspension in $0.45 \%$ glycerin saline solution (GSS) ${ }^{[7,8]}$ inside the plastic cuvette. A decrease of turbidity led to a decrease in optical density (OD) and an increase in the light transmission $(\% \mathrm{~T})$ that was detected by the detector. Changes of the OD, \%T, and hemolysis (as $\mathrm{HmFr}$ ) were plotted simultaneously in real-time mode and shown on the screen [Figure 1]. At $120 \mathrm{~s}$, the HA, expressed as HemeArea by the machine, was calculated and also shown on the screen. This HA was, in fact, the result of summation of $\mathrm{HmFr}$ which was automatically calculated by the following equation: $\left(\mathrm{OD}_{0}-\mathrm{OT}_{\mathrm{t}}\right) / \mathrm{OD}_{0}$, where $\mathrm{OD}_{0}$ and $\mathrm{OD}_{\mathrm{t}}$ represented the absorbance at 0 and 1-120 s, respectively.

Practically, after switching on the machine, the machine was set up to zero OD using distilled water and zero $\% \mathrm{~T}$ using black ink under the "SETUP" menu on the screen. Then, under the OD-TIME menu, mixture of $20 \mu \mathrm{L}$ ethylenediaminetetraacetic acid (EDTA) blood and $5 \mathrm{~mL}$ of $0.45 \%$ GSS was immediately put (within $10 \mathrm{~s}$ ) into the cuvette socket and "START" submenu of the OD-TIME menu simultaneously pressed. The real-time plot appeared until $120 \mathrm{~s}$ before an on-screen reporting of the "HemeArea or Hemolysis Area; $\mathrm{HA}^{\prime \prime}$ appeared [Figure 1].

\section{Blood samples}

Initially, 244 EDTA blood samples were randomly collected to determine the HA values among blood samples having positive, suspicious, and negative $0.36 \%$ NaCl-based OFT results, having the mean corpuscular volume $(\mathrm{MCV}) \leq 80 \mathrm{fL}$ and $>80 \mathrm{fL}$, and having mean corpuscular hemoglobin $(\mathrm{MCH}) \leq 27 \mathrm{pg}$ and $>27 \mathrm{pg}$. Next, 166 EDTA blood samples were collected for determination of the HA values in thalassemia traits having different globin gene genotypes and ROC analysis. The protocol of this study strictly followed the Declaration of Helsinki and was approved by the Institutional Research Ethics Committee.

\section{One-tube osmotic fragility test}

The conventional $0.36 \% \mathrm{NaCl}$-based OFT was performed with some modification. ${ }^{[9]}$ Briefly, $15 \mu \mathrm{L}$ of EDTA blood was mixed with $2 \mathrm{~mL}$ of $0.36 \% \mathrm{NaCl}$. Thereafter, the mixture was incubated at room temperature for $5 \mathrm{~min}$ before naked eye visualization of the results. If reddish-turbid suspension was seen, the result was positive. If reddish-clear solution was seen, the result was negative. However, if the appearance of the red cell suspension was between positive and negative results, it was reported as suspicious [Figure 2].

Determination of mean corpuscular volume and mean corpuscular hemoglobin

The MCV and $\mathrm{MCH}$ values were determined by an electronic blood cell counter (Sysmex KX21, Sysmex Corporation, Kobe, Japan) following manufacturer's instruction. Cutoff values for MCV and $\mathrm{MCH}$ were $80 \mathrm{fL}$ and $27 \mathrm{pg}$, respectively. ${ }^{[10,11]}$ The MCV values of $\leq 80 \mathrm{fL}$ and $\mathrm{MCH}$ of $\leq 27 \mathrm{pg}$ were classified as positive results.

\section{Determination hemoglobin E trait and identification of SEA- $\alpha$ thalassemia 1 and $\beta$-globin gene mutations}

$\mathrm{HbE}$ trait was identified by the cellulose acetate electrophoresis at alkaline condition in which $\mathrm{Hb}$ type was shown to be AE. ${ }^{[12,13]}$ The SEA- $\alpha$ thalassemia 1 deletion and $\beta$-thalassemia mutations including $\beta^{\mathrm{E}}$,

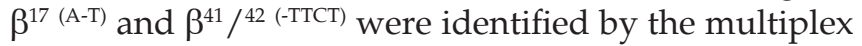
allele-specific polymerase chain reaction (PCR) described previously. ${ }^{[14]}$

\section{Determination and evaluation of cutoff points of "hemolysis area"}

Cutoff points of the HA values were determined by ROC analysis based on the definite diagnosis established by the standard method of cold alkaline extraction at alkaline condition, Gap-PCR, and allele-specific PCR described above. The area under the curve above 0.6 was considered significant for accurately determining the cutoff points. ${ }^{[15]}$ Sensitivity, specificity, positive predictive value (PPV), negative predictive value (NPV), and efficiency of the HA cutoff value in screening 


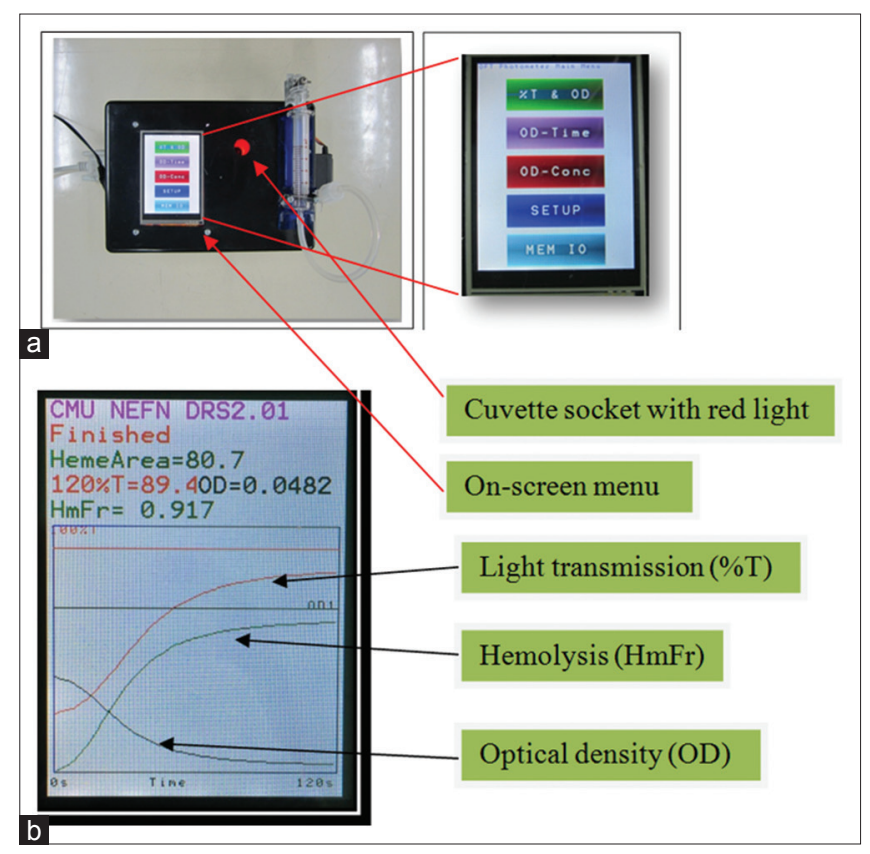

Figure 1: The newly invented portable spectrophotometer and the on-screen menu (a) as well as the on-screen test result (b) showing changes of light transmission (\%T), optical density, and hemolysis $(\mathrm{HmFr})$ of the tested sample. The numerical results are also shown at the top of the screen in panel $\mathrm{B}$. $\mathrm{HmFr}=\left(O D_{0}-O D_{t}\right) / O D_{0}$ where $O D_{0}$ was $O D$ at $0 \mathrm{~s}$ and $O D_{t}$ was $O D$ at $\left.1^{\text {st }}-120^{\text {th }} \mathrm{s}\right)$. HemeArea or hemolysis area $=\Sigma \mathrm{HmFr}$ taken at $1 \mathrm{~s}$ interval for 120 s. (Note: $\mathrm{HmFr}(120)$ could also be used as an osmotic fragility test selection parameter, similar to benchtop.)

thalassemia traits including $\mathrm{HbE}$, SEA- $\alpha$ thalassemia 1 , and $\beta$-heterozygotes were compared with those obtained from the conventional $0.36 \% \mathrm{NaCl}$-based OFT, $\mathrm{MCV}$, and $\mathrm{MCH}$.

\section{Statistical analysis}

Mean and standard deviation (SD) were computed to describe the analyzed data. Student's $t$-test and Pearson's correlation coefficient analysis were performed to compare mean and to correlate to analyzed data. All the statistical calculations were performed using statistical software. Statistical significance was considered if $P<0.001$.

\section{Results}

\section{Hematologic pictures of the initial 244 tested} samples

Hematologic parameters (mean $\pm \mathrm{SD}$ ) including $\mathrm{Hb}, \mathrm{Hct}$, $\mathrm{MCV}, \mathrm{MCH}$ and HA in 244 initial tested EDTA blood samples were $12.8 \pm 1.4 \mathrm{~g} / \mathrm{dL}, 39.3 \% \pm 4.1 \%, 80.1 \pm 7.9 \mathrm{fL}$, $26.2 \pm 3.0 \mathrm{pg}$ and $54.6 \pm 19.9$ units, respectively. Sixty-nine (28.3\%) blood samples had positive OFT result while $156(63.9 \%)$ and $19(7.8 \%)$ blood samples had negative OFT and suspicious OFT results, respectively. A hundred and nine $(44.7 \%)$ blood samples had MCV $\leq 80 \mathrm{fL}$ while 135 (55.3\%) blood samples had MCV >80 fL. Finally, $\mathrm{MCH}$ values $\leq 27 \mathrm{pg}$ and $>27 \mathrm{pg}$ were seen in $138(56.6 \%)$ and $106(43.4 \%)$ blood samples, respectively.

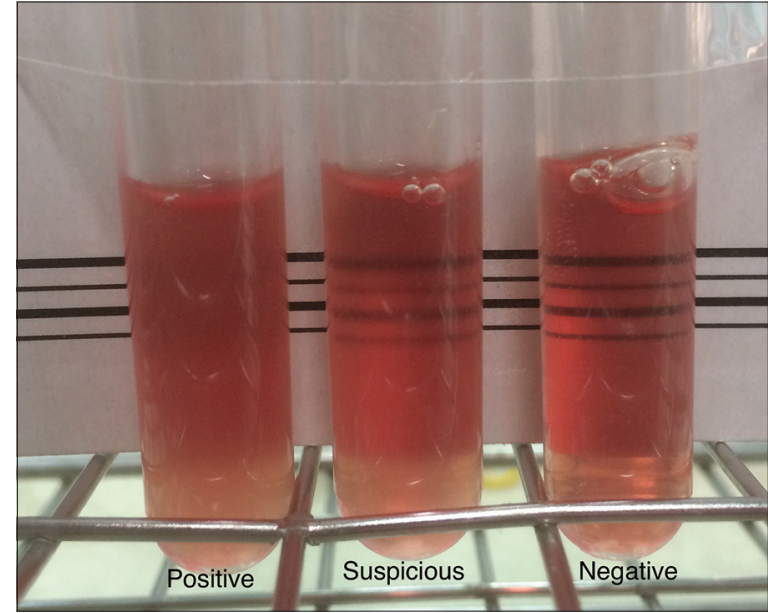

Figure 2: Appearance of the $0.36 \% \mathrm{NaCl}$-based osmotic fragility test results as visualized by naked eyes. The result is written under each tube in which the reddish-turbid RBC suspension is reported as positive, reddish-clear red blood cell solution as negative. The tube with RBC suspension having the appearance between positive and negative result is reported as suspicious

Hemolysis area in samples having different mean corpuscular volume, mean corpuscular hemoglobin, and osmotic fragility test results Analysis of HA and MCV showed that the HA values correlated significantly with the MCV values $(r=0.65$, $P<0.001)$. When samples were grouped by the MCV values, $\leq 80 \mathrm{fL}$ and $>80 \mathrm{fL}$, the HA values in the first group was significantly lower than the second one $(43.1 \pm 19.6$ vs. $63.8 \pm 14.5, P<0.001)$ [Figure 3].

The HA values also positively and significantly correlated with the MCH $(r=0.65, P<0.001)$. Those samples having $\mathrm{MCH} \leq 27 \mathrm{pg}$ had significantly lower levels of HA than the samples having $\mathrm{MCH}>27 \mathrm{pg}$ $(46.7 \pm 20.1$ vs. $64.8 \pm 14.2, P<0.001)$ [Figure 4].

The HA values in blood samples having different OFT results were also heterogeneous. Blood samples having positive OFT results had the smallest HA values $(33.3 \pm 14.4)$ while blood samples having negative OFT results had the largest HA values $(65.3 \pm 13.4)$. In addition, blood samples having suspicious OFT results had the HA value of $42.9 \pm 10.5$. All these HA values were significantly different [Figure 5].

The hemolysis area values in samples having different thalassemia genotypes

One hundred and sixty-six blood samples including normal individuals, $\mathrm{HbE}$ trait $\left[\beta^{\mathrm{E}} / \beta^{\mathrm{A}}\right]$, SEA- $\alpha$ thalassemia 1 trait $(--\operatorname{SEA} / \alpha \alpha)$, $\beta$-thalassemia trait $\left(\beta^{17} / \beta^{\mathrm{A}}, \beta^{41 / 42} / \beta^{\mathrm{A}}\right)$, and double $\mathrm{HbE} / \mathrm{SEA}-\alpha$ thalassemia 1 traits $\left(\beta^{\mathrm{E}} / \beta^{\mathrm{A}}\right.$ and -.- SEA $\left./ \alpha \alpha\right)$ were recruited to determine and compare the HA values. All samples were not anemic as indicated by high $\mathrm{Hb} / \mathrm{Hct}$ levels, and $\mathrm{MCV}$ and $\mathrm{MCH}$ levels were unique for each type of thalassemia as shown in Table $1 .^{[12,16]}$ The HA value of each thalassemia 


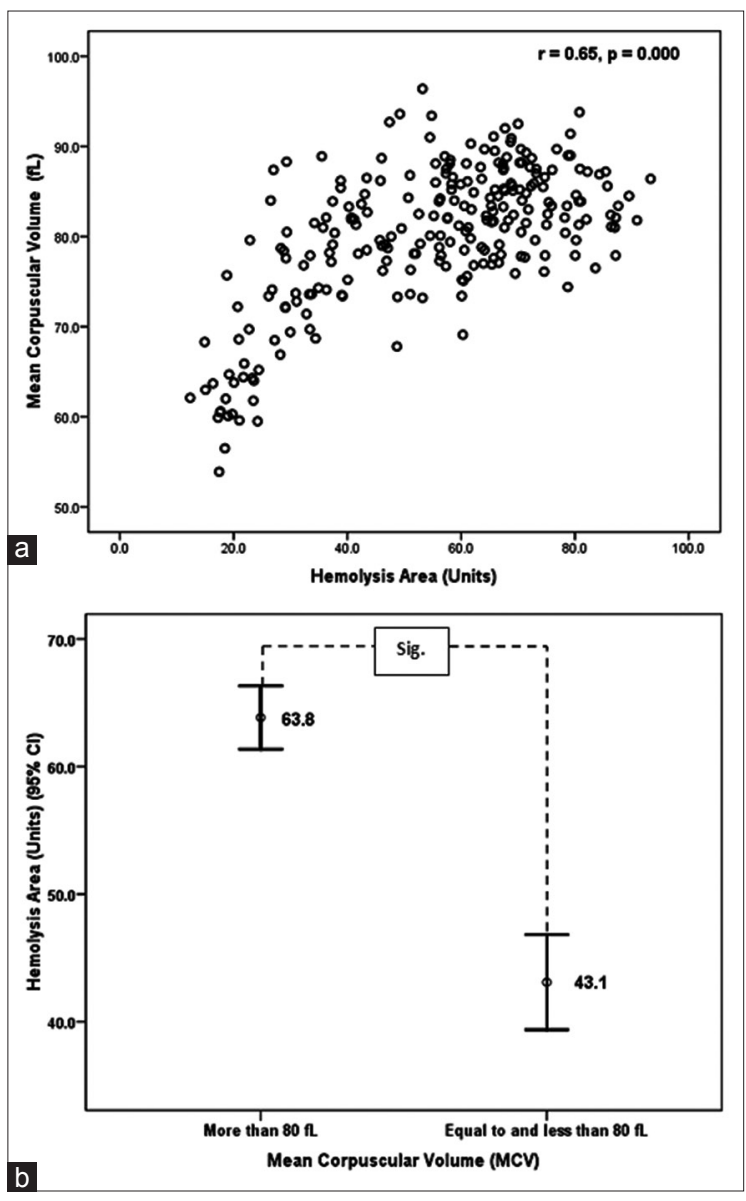

Figure 3: Relationship of hemolysis area and mean corpuscular volume values (a) and comparison of hemolysis area values in blood samples having mean corpuscular volume $>80 \mathrm{fL}$ and $\leq 80 \mathrm{fL}$ (b). Mean values are placed at the middle of each error bar. "Sig." indicates statistically significant difference after Student's $t$-test analysis

genotype is also shown in Table 1. Initial comparison of the HA values showed that the HA values in normal samples were significantly higher than those in $\mathrm{HbE}$ trait $(P<0.001)$, which also were significantly higher than those in SEA- $\alpha$ thalassemia 1, $\beta$-thalassemia, and double $\mathrm{HbE} / \mathrm{SEA}-\alpha$ thalassemia 1 traits. The HA values in the SEA- $\alpha$ thalassemia $1, \beta$-thalassemia, and double $\mathrm{HbE} / \mathrm{SEA}-\alpha$ thalassemia 1 traits were statistically identical $(P>0.001)$ [Figure 6].

\section{Determination and evaluation of cutoff value of "hemolysis area"}

It was clearly shown in previous section that the HA values were different among normal and thalassemia traits. The cutoff value of HA to differentiate between normal and thalassemia trait was then determined by the ROC analysis. The cutoff point was found to be 52.4, which had sensitivity of 0.908 and specificity of 0.915 [Figure 7]. Normal individuals had the HA value of more than or equal to 52.4 while the thalassemia traits had the HA value of $<52.4$.

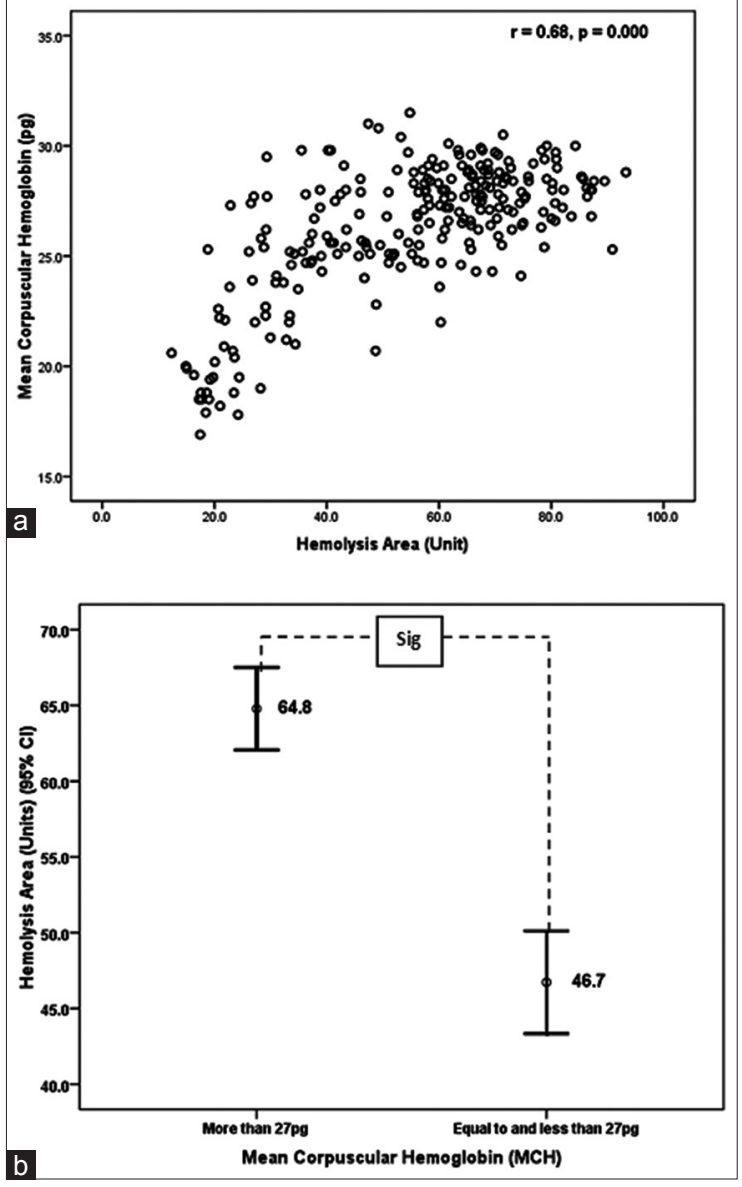

Figure 4: Relationship of hemolysis area and mean corpuscular hemoglobin values (a) and comparison of hemolysis area values in samples having mean corpuscular hemoglobin $>27 \mathrm{pg}$ and $\leq 27 \mathrm{pg}$ (b). Mean values are placed at the middle of each error bar. "Sig." indicates statistically significant difference after Student's $t$-test analysis

Table 1: Red cell parameters and hemolysis area values (mean \pm standard deviation) in different types of thalassemia mutations

\begin{tabular}{|c|c|c|c|c|c|}
\hline & $\mathrm{Hb}(\mathrm{g} / \mathrm{dL})$ & Hct (\%) & MCV (fL) & $\mathrm{MCH}(\mathrm{pg})$ & HA \\
\hline ormal (119) & & $40.7 \pm 4.2$ & & $28.1 \pm 1.6$ & $67.1 \pm 12.6$ \\
\hline $\mathrm{oE}$ trait $(31)$ & & & & & \\
\hline EAT (7) & $11.3 \pm 0.9$ & $36.4 \pm 2.1$ & $63.1 \pm 3.5$ & $19.5 \pm 1.2$ & $20.2 \pm 4.8$ \\
\hline & & $35.5 \pm 2.1$ & 58.7 & & \\
\hline ET/SEAT (6) & 11. & $35.3 \pm 2.9$ & $65.2 \pm 4.1$ & & 22. \\
\hline MIxed (16) & $11.3 \pm 0.9$ & $35.8 \pm 2.4$ & $63.0 \pm 4.3$ & $19.9 \pm 1.8$ & $20.7 \pm 6.3$ \\
\hline \multicolumn{6}{|c|}{$\begin{array}{l}\text { Numbers in parentheses of the first column are sample sizes. Normal }=\text { Normal } \\
\text { or nonclinically significant thalassemia, SEAT = SEA- } \alpha \text { thalassemia } 1 \text { trait, } \mathrm{BT}= \\
\beta \text {-thalassemia trait, } \mathrm{HbE} / \mathrm{SEAT}=\text { Double HbE/SEA- } \alpha \text { thalassemia } 1 \text { trait, Mixed } \\
=\text { Combine SEA- } \alpha \text { thalassemia } 1 \text { trait, } \beta \text {-thalassemia trait, and double HbE/ } \\
\text { SEA- } \alpha \text { thalassemia } 1 \text { trait, } \mathrm{Hb}=\text { Hemoglobin, } \mathrm{Hct}=\text { Hematocrit, MCV }=\text { Mean } \\
\text { corpuscular volume, } \mathrm{MCH}=\text { Mean corpuscular hemoglobin, } \mathrm{HA}=\mathrm{Hemolysis} \text { area }\end{array}$} \\
\hline
\end{tabular}

The capacity of the newly established HA cutoff point in screening thalassemia traits was found to be comparable to that of the conventional $0.36 \% \mathrm{NaCl}$-based OFT, $\mathrm{MCV}$, and $\mathrm{MCH}$ [Table 2]. The 52.4 cutoff point of the HA value was capable to clearly classified blood samples having negative $0.36 \% \mathrm{NaCl}$-based OFT results 
from blood samples having positive and suspicious $0.36 \% \mathrm{NaCl}$-based OFT results [Figure 8]. Moreover, the blood samples having discordant results obtained $0.36 \% \mathrm{NaCl}$-based OFT; for example, $\mathrm{HbE}$ trait ["E" in Figure 8] having negative $0.36 \% \mathrm{NaCl}$-based OFT result, SEA- $\alpha$ thalassemia 1 trait, and double SEA- $\alpha$ thalassemia 1 trait ["SEA" and "SEA/E" in Figure 8, respectively] having suspicious $0.36 \% \mathrm{NaCl}$-based OFT result clearly had the HA values $<52.4$ cutoff point.

Most importantly, using 52.4 cutoff point, the large proportion of the $\mathrm{HbE}$ trait was screened in compared to the conventional $0.36 \% \mathrm{NaCl}$-based OFT as shown

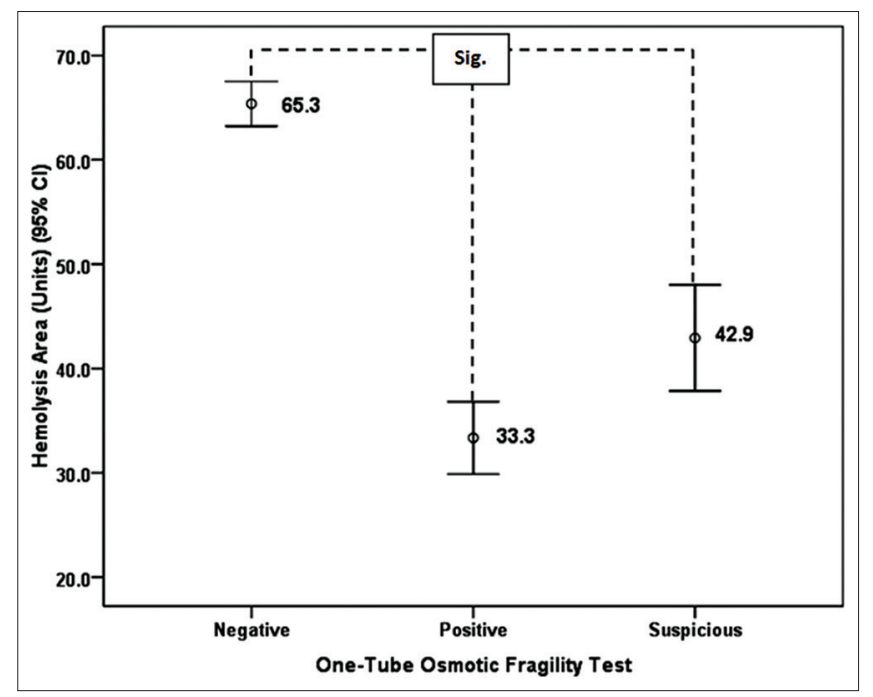

Figure 5: Comparison of hemolysis area values in samples having positive, negative, and suspicious $0.36 \% \mathrm{NaCl}$-based osmotic fragility test results. Mean values are placed at the middle of each error bar. "Sig." indicates statistically significant difference after Student's $t$-test analysis. Note that hemolysis area values in osmotic fragility test-negative group are much higher than those in osmotic fragility test-positive and osmotic fragility test-negative groups

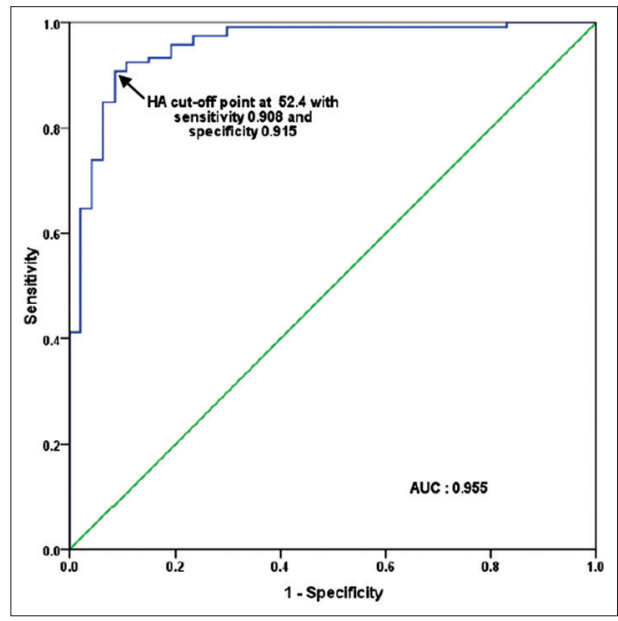

Figure 7: Receiver operation curve for determination of cutoff values of hemolysis area that will be used to screen thalassemia trait from normal or nonclinically significant thalassemia. The point where the hemolysis area cutoff value of 52.4 unit is placed is arrowed. Area under curve stands for area under curve in Table 3.

\section{Discussion}

Thalassemia traits can only be detected by the laboratory investigations as they have no obvious clinical symptoms. One-tube OFT is the screening test for thalassemia traits that is widely employed in many thalassemia-rich countries. At present, two salt solutions are used for OFT, including $0.36 \% \mathrm{NaCl}$ solution ${ }^{[5,9,17]}$ and $0.45 \%$ GSS. ${ }^{[7,18]}$ The $0.36 \% \mathrm{NaCl}$-based OFT requires naked eye visualization for result reading whereas numerical data of hemolysis (\% hemolysis) are generated in the $0.45 \%$ GSS-based OFT. The later method can overcome the interobserver variation which is common in the

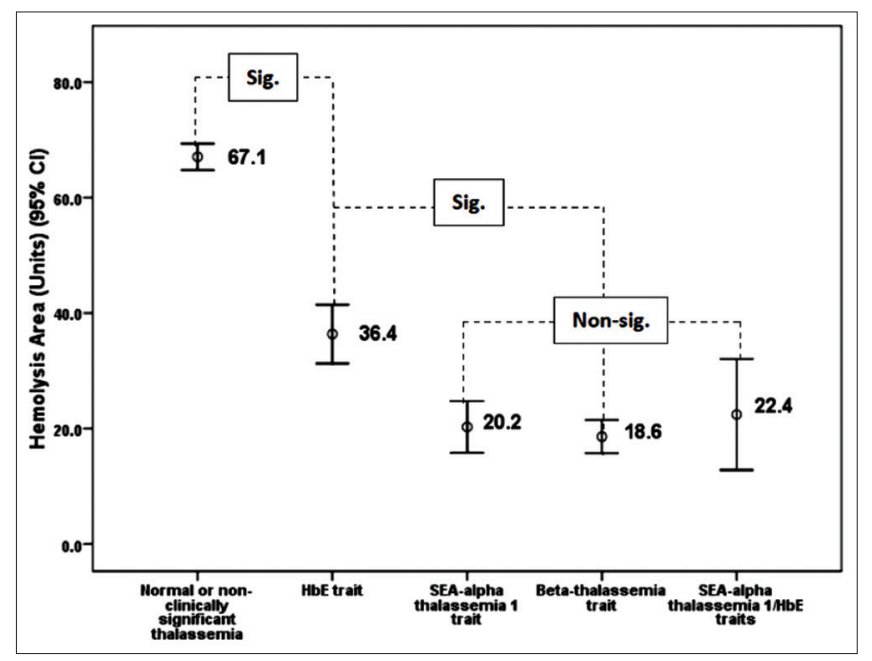

Figure 6: Comparison of hemolysis area values among blood samples having different thalassemia mutations. Mean values are placed at the middle of each error bar. "Sig." and "Nonsig" indicate statistically significant and nonsignificant difference, respectively, after Student's $t$-test analysis

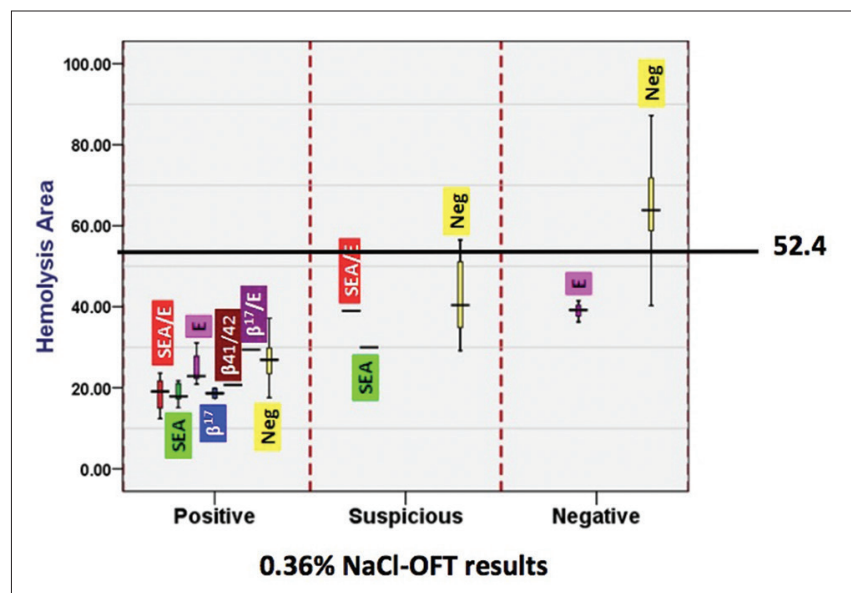

Figure 8: The hemolysis area values and results of $0.36 \% \mathrm{NaCl}$-based osmotic fragility test in blood samples having different thalassemia genotypes. The data were presented in box plots with a line of 52.4 cutoff point drawn. The full descriptions of "SEA," " $\beta^{4141}$," " $\beta$ 17," "E," and "neg" can be seen in the text. Note that thalassemia trait with positive and suspicious $0.36 \% \mathrm{NaCl}$-based osmotic fragility test results all had the hemolysis area values of $<52.4$ 
Table 2: Evaluation of Hemolysis Area (HA) at 52.4 cutoff, $0.36 \% \mathrm{NaCl}$-based osmotic fragility test (OFT), mean corpuscular volume at $80 \mathrm{fL}$ cutoff, and mean corpuscular hemoglobin at $27 \mathrm{pg}$ cut-off point (MCH) in screening carriers of HbE, SEA- $\alpha$ thalassemia 1 and $\beta$-thalassemia

\begin{tabular}{lccccc}
\hline & Sensitivity (\%) & Specificity (\%) & PPV (\%) & \multicolumn{2}{c}{ NPV (\%) } \\
\hline HA & 91.5 & 90.8 & 79.6 & 96.4 & 90.4 \\
OFT & 80.9 & 96.6 & 90.5 & 92.7 & 92.2 \\
MCV & 87.2 & 94.1 & 85.4 & 94.9 & 97.2 \\
MCH & 89.4 & 75.6 & 59.2 & 94.7 & 79.5 \\
\hline
\end{tabular}

OFT = Osmotic fragility test, MCV = Mean corpuscular volume, $\mathrm{MCH}=$ Mean corpuscular hemoglobin, $\mathrm{PPV}=\mathrm{Positive} \mathrm{predictive} \mathrm{value,} \mathrm{NPV} \mathrm{=} \mathrm{Negative} \mathrm{predictive}$ value, $\mathrm{HA}=$ Hemolysis area

Table 3: Comparison of hemolysis area cutoff value at 52.4 and $0.36 \% \mathrm{NaCl}$-based osmotic fragility test in screening $\mathrm{HbE}$ trait

\begin{tabular}{lc}
\hline Tests and Results & Numbers (\%) \\
\hline OFT $(n=36)$ & \\
Negative & $9(25)$ \\
Positive & $25(69.4)$ \\
Suspicious & $2(5.6)$ \\
HA $(n=36)$ & \\
$\geq 52.4$ & $4(11.1)$ \\
$<52.4$ & $32(89.9)$ \\
\hline
\end{tabular}

former $0.36 \% \mathrm{NaCl}$-based OFT method. However, this test cannot be performed in fieldwork since it needs benchtop spectrophotometer to measure change of OD for calculating the "\% hemolysis." The portable spectrophotometer with the built-in capacity of calculating the new parameter of HA invented in this study overcomes the aforementioned obstacles.

This portable spectrophotometer was $20 \mathrm{~cm} \times 13 \mathrm{~cm} \times 8 \mathrm{~cm}$ in dimension, weighing only $0.5 \mathrm{~kg}$. Thus, it can be carried to the field site where thalassemia screen is usually performed. The HA was calculated at $120 \mathrm{~s}$ for each sample. This hence made the new platform able to swiftly screen the thalassemia trait in the field work.

The samples having positive/suspicious OFT, $\mathrm{MCV} \leq 80 \mathrm{fL}$, and $\mathrm{MCH} \leq 27 \mathrm{pg}$ had significantly lower $\mathrm{HA}$ values than those having negative $\mathrm{OFT}, \mathrm{MCV}>80 \mathrm{fL}$, and $\mathrm{MCH}>27 \mathrm{pg}$. This was as expected as low HA values indicated decreased rate of hemolysis. The decreased rate of hemolysis and small and less hemoglobinized red blood cell are observed in all types of severe thalassemia heterozygote as indicated by positive OFT, low MCV, and low $\mathrm{MCH}$ values, respectively. ${ }^{[5,9,17,19-21]}$ This result thus confirmed the ability of the HA values in effective screening the thalassemia traits. However, the HA values might not correlate with $\mathrm{MCV} / \mathrm{MCH}$ values in sickle cell trait or in some samples having dimorphic erythrocytes. In the sickle cell trait, although the osmotic fragility of red blood cells is reduced, i.e., positive OFT test, the $\mathrm{MCV}$ tends to be within normal range. ${ }^{[5,22,23]}$ Moreover, dimorphic red blood cells possessing a mixture of microcytic and normal red blood cells may be seen in the early phase of iron depletion and position treatment of iron deficiency anemia. ${ }^{[2]}$ The red blood cells in these conditions tend to have normal MCV value while the osmotic fragility is decreased. Therefore, in situation, where the $\mathrm{HA}$ values and $\mathrm{MCV} / \mathrm{MCH}$ values do not agree, these conditions must be concerned.

Cutoff value is essential for the HA-based OFT and ROC analysis established the cutoff value of 52.4. Those samples having HA $\leq 52.4$ and $>52.4$ were interpreted as positive and negative for the test, respectively. Comparable sensitivity, specificity, PPV, NPV, and efficiency of HA-based OFT to those of conventional $0.36 \% \mathrm{NaCl}$-based OFT, MCV, and $\mathrm{MCH}$ as shown in Table 3 should indicate that the HA-based OFT can also be used in thalassemia screen. ${ }^{[9,11,21]}$ Analysis in detail as shown in Figure 8 demonstrated that the 52.4 cutoff of $\mathrm{HA}$ value was superior to the conventional $0.36 \%$ $\mathrm{NaCl}$-based OFT in screening for thalassemia traits. This was because all the thalassemia trait having negative and suspicious OFT results had the HA values $<52.4$ cutoff points. However, some samples having negative PCR results had the HA value $<52.4$ cutoff point as shown in Figure 8. This can be simply explained by the fact that the PCR protocol used in this study was set up to detect only the SEA type of $\alpha$-thalassemia 1 ["SEA" in Figure 8], TTCT-deletion at CDs $41 / 42$ of $\beta$-globin gene

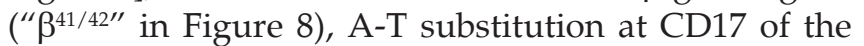
$\beta$-globin gene [" $\beta$ 17" in Figure 8], and G-A substitution at $\mathrm{CD} 26$ of the $\beta$-globin gene or $\mathrm{HbE}$ [" $\mathrm{E}^{\prime \prime}$ in Figure 8]. Thus, those blood samples having negative PCR results might have other to be elucidated thalassemia genotypes.

This HA value is closed to $60 \%$ hemolysis cutoff originally set for $0.45 \%$ GSS-based OFT. ${ }^{[8]}$ Sensitivity, specificity, PPV, and NPV of the HA-based OFT in detecting thalassemia traits were $91.5 \%, 90.8 \%, 79.6 \%$, and $96.4 \%$, respectively, compared to $97.6 \%, 72.9 \%, 33.6 \%$, and $99.5 \%$ by the original $0.45 \%$ GSS-based OFT. ${ }^{[18]}$ Although the HA-based OFT had lower sensitivity than the original $0.45 \%$ GSS-based OFT, it had higher specificity and PPV than the original test. This meant that the HA-based OFT was more effective in detecting thalassemia heterozygote than the original test. 
The $0.36 \% \mathrm{NaCl}$-based OFT and red cell indices can generate falsely negative result for $\mathrm{HbE}$ trait. In the study of Kattamis et al., 32\% of $\mathrm{HbE}$ trait had falsely negative $0.36 \% \mathrm{NaCl}$-based OFT results. ${ }^{[5]}$ A resembling result was also observed in this study in which $25 \%$ of the $\mathrm{HbE}$ heterozygote had negative result of $0.36 \%$ NaCl-based OFT. More importantly, the HA-based OFT demonstrated only $11.1 \%$ falsely negative results for $\mathrm{HbE}$ trait. This result should indicate that the HA-based OFT was more efficient in screening $\mathrm{HbE}$ trait than the original $0.36 \% \mathrm{NaCl}$-based OFT.

\section{Conclusion}

The novel platform of one-tube OFT for thalassemia screen was established relying on the use of new parameter so-called HA. The HA generated by the newly invented portable spectrophotometer with the cutoff point of 52.4 was effective in screening thalassemia traits. This new platform could then be an alternative option of thalassemia screen in thalassemia-rich nations.

\section{Financial support and sponsorship Nil.}

\section{Conflicts of interest}

There are no conflicts of interest.

\section{References}

1. Flint J, Harding RM, Boyce AJ, Clegg JB. The population genetics of the haemoglobinopathies. In: Rodgers GP, editor. Bailliere's Clinical Haematology, International Practice and Research: Sickle Cell Disease and Thalassaemia. Vol. 11. London: Bailliere Tindall; 1998. p. 1-51.

2. Hill AV. Molecular epidemiology of the thalassaemias (including haemoglobin E). Baillieres Clin Haematol 1992;5:209-38.

3. Weatherall DJ, Clegg JB. Thalassemia - A global public health problem. Nat Med 1996;2:847-9.

4. Weatherall DJ. Phenotype-genotype relationships in monogenic disease: Lessons from the thalassaemias. Nat Rev Genet 2001;2:245-55.

5. Kattamis C, Efremov G, Pootrakul S. Effectiveness of one tube osmotic fragility screening in detecting beta-thalassaemia trait. J Med Genet 1981;18:266-70.

6. Thomas S, Srivastava A, Jeyaseelan L, Dennison D, Chandy M. NESTROFT as a screening test for the detection of thalassaemia \& common haemoglobinopathies - An evaluation against a high performance liquid chromatographic method. Indian J Med Res 1996;104:194-7.

7. Flatz SD, Flatz G. Population screening for beta-thalassaemia. Lancet 1980;2:495-6.

8. Sanguansermsri T, Phumyu N, Chomchuen S, Steger HF. Screening for alpha-thalassemia-1 heterozygotes in expecting couples by the combination of a simple erythrocyte osmotic fragility test and a PCR-based method. Community Genet 1999;2:26-9.

9. Winichagoon $\mathrm{P}$, Thitivichianlert A, Lebnak T, Piankijagum A, Fucharoen S. Screening for the carriers of thalassemias and abnormal hemoglobins at the community level. Southeast Asian J Trop Med Public Health 2002;33 Suppl 2:145-50.

10. Old JM, Olivieri NF, Thein SL. Diagnosis and management of thalassemia: Avoidance and population control. In: Weatherall DJ, Clegg JB, editors. The Thalassemia Syndrome. $4^{\text {th }}$ ed. Milan: Rotolito Lombarda SpA; 2001. p. 597-629.

11. Sirichotiyakul S, Maneerat J, Sa-nguansermsri T, Dhananjayanonda P, Tongsong T. Sensitivity and specificity of mean corpuscular volume testing for screening for alpha-thalassemia-1 and beta-thalassemia traits. J Obstet Gynaecol Res 2005;31:198-201.

12. Fucharoen $S$, Weatherall DJ. The hemoglobin E thalassemias. Cold Spring Harb Perspect Med 2012;2:pii: a011734.

13. Weatherall DJ, editor. The Thalassemia. New York: Churchill Livingstone; 1983.

14. Tatu T, Kiewkarnkha T, Khuntarak S, Khamrin S, Suwannasin S, Kasinrerk $\mathrm{W}$, et al. Screening for co-existence of $\alpha$-thalassemia in $\beta$-thalassemia and in $\mathrm{HbE}$ heterozygotes via an enzyme-linked immunosorbent assay for $\mathrm{Hb}$ Bart's and embryonic $\zeta$-globin chain. Int J Hematol 2012;95:386-93.

15. Park SH, Goo JM, Jo CH. Receiver operating characteristic (ROC) curve: Practical review for radiologists. Korean J Radiol 2004;5:11-8.

16. Weatherall DJ, Clegg JB. The Thalassaemia Syndromes. $4^{\text {th }}$ ed. Oxford: Blackwell Scientific; 2001.

17. Singh SP, Gupta SC. Effectiveness of red cell osmotic fragility test with varying degrees of saline concentration in detecting beta-thalassaemia trait. Singapore Med J 2008;49:823-6.

18. Sirichotiyakul S, Tantipalakorn C, Sanguansermsri T, Wanapirak C, Tongsong T. Erythrocyte osmotic fragility test for screening of alpha-thalassemia- 1 and beta-thalassemia trait in pregnancy. Int J Gynaecol Obstet 2004;86:347-50.

19. Deng J, Liu X, Liu Y. Evaluation of red cell mean corpuscular volume and simple tube red cell osmotic fragility quantitative test in detection of thalassemia. Zhonghua Fu Chan Ke Za Zhi 2000;35:610-2.

20. Karimi M, Rasekhi AR. Efficiency of premarital screening of beta-thalassemia trait using $\mathrm{MCH}$ rather than $\mathrm{MCV}$ in the population of Fars Province, Iran. Haematologia (Budap) 2002;32:129-33.

21. Pranpanus S, Sirichotiyakul S, Srisupundit K, Tongsong T. Sensitivity and specificity of mean corpuscular hemoglobin $(\mathrm{MCH})$ : For screening alpha-thalassemia- 1 trait and beta-thalassemia trait. J Med Assoc Thai 2009;92:739-43.

22. Osei-Hwedieh DO, Kanias T, Croix CS, Jessup M, Xiong Z, Sinchar D, et al. Sickle cell trait increases red blood cell storage hemolysis and post-transfusion clearance in mice. EBioMedicine 2016;11:239-48.

23. Velasco-Rodríguez D, Alonso-Domínguez JM, González-Fernández FA, Muriel A, Abalo L, Sopeña M, et al. Laboratory parameters provided by Advia 2120 analyser identify structural haemoglobinopathy carriers and discriminate between $\mathrm{Hb}$ S trait and Hb C trait. J Clin Pathol 2016;69:912-20.

24. Constantino BT. The red cell histogram and the dimorphic red cell population. Lab Med 2011;42:300-8. 